\title{
Natural Hazard Influence Model of Maintenance and Repair Cost for Sustainable Accommodation Facilities
}

\author{
Sang-Guk Yum ${ }^{1}{ }^{\mathbb{D}}$, Ji-Myong $\mathrm{Kim}^{2}$ and Kiyoung Son ${ }^{3, *}$ \\ 1 Department of Civil Engineering and Engineering Mechanics, Columbia University, New York, NY 10027, \\ USA; sy2509@columbia.edu \\ 2 Department of Architectural Engineering, Mokpo National University, Mokpo 58554, Korea; \\ jimy@mokpo.ac.kr \\ 3 School of Architectural Engineering, Ulsan University, Ulsan 44610, Korea \\ * Correspondence: sky9852111@ulsan.ac.kr
}

Received: 28 May 2020; Accepted: 17 June 2020; Published: 18 June 2020

check for updates

\begin{abstract}
To optimally maintain buildings and other built infrastructure, the costs of managing them during their entire existence- that is, lifecycle costs—-must be taken into account. However, due to technological improvements, developers now build more high-rise and high-performance buildings, meaning that new approaches to estimating lifecycle costs are needed. Meanwhile, an accelerating process of industrialization around the world means that global warming is also accelerating, and the damage caused by natural disasters due to climate change is increasing. However, the costs of losses related to such hazards are rarely incorporated into lifecycle-cost estimation techniques. Accordingly, this study explored the relationship between, on the one hand, some known parameters of natural disasters, such as earthquakes, high winds, and/or flooding, and on the other hand, the data on exceptional maintenance costs, represented by gross loss costs, generated by a large international hotel chain from 2007 to 2017. The regression model used revealed a correlation between heavy rain and insurance-claim payouts. This and other results can usefully inform safety and design guidelines for policymakers, both in disaster management and real estate, as well as in insurance companies
\end{abstract}

Keywords: natural disaster; risk management; accommodations; operations and maintenance; lifecycle cost; disaster management

\section{Introduction}

As the sizes and heights of buildings continue to increase, new approaches for estimating and managing their lifecycle costs have become necessary [1,2]. Construction's impacts on development, society, the environment, and the economy should all be considered as fundamental to considerations of long-term building sustainability. Accordingly, an increasing number of studies are being conducted on buildings' social impacts, including numbers of fatalities during disasters; environmental ones such as $\mathrm{CO}_{2}$ emissions during deconstruction/demolition; and economic ones such as natural-disaster-related repair costs [3-6]. According to the Intergovernmental Panel on Climate Change [7], average global temperatures have been rising, making natural disasters such as typhoons both more frequent and less predictable. It is therefore very important to assess the maintenance and repair costs that have been associated with such natural disasters in the past as a means of anticipating such costs going forward. Due not only to the increased likelihood of various types of damage related to global warming but also to public demand for greater urban-system resilience, effective estimation of such future costs should comprehensively incorporate those factors that may require structural repair or complete replacement [8]. For this study, hotel facilities were chosen because the hotel business is perhaps uniquely vulnerable to the negative consequences of both poorly maintained facilities and natural 
disasters [9]. Yet, despite the profound impact that the cosmetic appearance of a building can have on hotel revenues, and despite the long lifespans and considerable age of many hotel buildings, their natural-disaster management tends to be passive rather than proactive, unsystematic, and poorly funded relative to their overall budgets $[10,11]$.

\subsection{Research Background}

Building maintenance costs are increasing due to the greater frequency of natural disasters and the generally greater heights of new commercial buildings $[8,12]$. To address this challenge, effective management should take into account the specific features of every building, along with a comprehensive range of factors that might cause that building's functionality to deteriorate. In recent decades, many property managers have applied asset-management techniques to more efficiently deal with the maintenance costs incurred in the operating stage, which account for the highest proportion of any building's total lifecycle costs [13], the other stages being planning, feasibility studies, basic design, execution design, construction, and demolition. However, asset management can be difficult for many entities to implement since, as well as being building-specific, it requires information compatibility across all stages of the building's lifecycle, massive quantities of maintenance materials, and long-term investment. A considerable body of asset-management research is devoted to mitigating these drawbacks, but such studies rarely consider the relationship between natural disasters and maintenance costs. The present paper addresses this gap in the literature, using 11 years of data on an international hotel chain's insurance-claim payouts.

\subsection{Research Objective}

A hotel chain was chosen as this study's research case because an insurance company was willing to provide the researchers with gross loss data on that chain's claim payouts. First, this paper contains a review of the prior research on asset management as it relates to building lifecycles. Second, it features hotel property-loss data on the 2007-2017 period, including the gross loss, loss factor, and date of loss, to explore the relationships between natural-hazard factors and operation and management costs. Finally, this paper includes a regression analysis of the data collected to identify the correlations among maintenance costs, damage, and the incidence and intensity of earthquakes, high winds, and flooding.

\section{Literature Review}

Facility management comprises professional methodologies aimed at ensuring the functionality of properties and built environments (International Facility Management Association, 1992, 2015). Its techniques, which include lifecycle-cost estimation, address safety and durability, as well as economic considerations [14]. Lee and Jung's [15] comparison of facility-management practices in the United States, Canada, Australia, and South Korea suggests that, although all four countries focused on the operation and management stage, which occupies, on average, $85 \%$ of the building lifecycle [13], only Australia emphasized a lifecycle-cost approach to managing costs. Specifically, Lee and Jung [15] conducted a high-volume review of the existing literature on applied facility management and categorized this discipline's functions into 19 types, covering property, service, space, communication, energy, environment, equipment, moves, quality, security, costs, documents, human resources, materials, outsourcing, regulations, schedules, technology, and general management.

Yu et al. [16] proposed a methodology for developing facility-management functions and their computerization. Foster [17] emphasized the importance of operation and management costs, especially energy costs, which account for $25 \%$ of all operation costs, but which many U.S. federal buildings were found to neglect. The same author also advocated the establishment of a strategy to reduce energy costs in the operation and management stage. Williams et al. [18] investigated the potential usage of building information modeling (BIM) in facility management using a survey and interviews to explore the gaps between real-world applications and common perceptions. They found that, although there was still a need to improve and educate facility-management professionals about real-world utilization 
of BIM, this approach to facility management should be adopted due to its usefulness not only for information exchange but also for collaboration among construction stakeholders.

Lifecycle costs have also been recognized as an important basis for the improvement of structural resilience, and in that context, American Society for Testing and Materials (ASTM) $[19,20]$ developed a standard for the quantification and specification of costs at each stage of a building's lifecycle to produce more accurate lifecycle-cost estimates. Several researchers have also developed methodologies for improving lifecycle-cost assessments, with some focusing on costs during the early design process of buildings and other types of infrastructure. For example, matrix-based frameworks for choosing cost-efficient materials were investigated by Pettang et al. [21], whose estimates of projects' construction costs included labor, materials, and operation and management costs, in an effort to support decision making by construction stakeholders in a range of material scenario. Later, Günaydın and Doğan [22] proposed a novel cost-estimation approach based on artificial neural networks (ANNs) but, again, focused on the early stage of building construction. Another approach to creating an accurate construction-cost estimation model, developed by Kim et al. [23], was built around three different methods-statistical analysis (regression modeling), ANNs, and case-based reasoning-and established that it could effectively manage construction projects' costs in their early stages. However, their approach did not consider long-term operation and management costs despite the fact that they account for $85 \%$ of lifecycle costs [7].

The effects of aging on buildings were investigated by Rahman et al. [24], who proposed a decision framework for simultaneously evaluating various criteria, including resilience, energy, cost-effectiveness, durability, and environment. They concluded that multiple aspects of building performance should be considered during the operation and management stage, and the materials should be altered accordingly. Another perspective on lifecycle costs focused on energy consumption has arisen amid the development of advanced building materials and technologies with the potential to make buildings more energy-efficient, which in turn, would likely reduce costs and lessen environmental impacts [12]. For example, Hasan [25] used lifecycle-cost assessment to optimize wall thickness for purposes of insulation; Kneifel [26] investigated the effects of energy-efficient design on commercial buildings' lifecycle costs, energy consumption, and carbon emissions; Morrissey and Horne [27] studied the interrelationships of new buildings' thermal properties, initial construction costs, and whole-life energy costs; and Gluch and Baumann [28] applied the concept of lifecycle costs to a proposed framework for eco-friendly decision making.

In addition to investigating tools and techniques for the effective management for high-performance buildings, such as increasing their energy efficiency as discussed above, a comprehensive lifecycle assessment still needs to take into account the repair costs arising from natural hazards if overall asset management is to be effective. Prior research has utilized building characteristics such as height, area, and price as variables for the extent of damage to properties $[29,30]$. According to those studies, building height had a clear statistical relationship with financial losses caused by natural hazards, notably windstorms.

As well as the relationships between building features such as height and losses from natural hazards, some researchers have emphasized the importance to lifecycle costs of damage by such hazards, despite the inherent randomness with which such events strike, both by building type and geographically. As noted by Chang and Shinozuka [31] in connection with the 1994 Northridge (USA) and 1995 Kobe (Japan) earthquakes, it is tempting to neglect the potential for damage by natural disasters when estimating the lifecycle costs of infrastructure systems due to these many uncertainties. However, through a case study of pipeline systems, they demonstrated the value of extending traditional lifecycle-cost assessment to include potential repair costs and related user costs arising from earthquake damage. Similarly, Wei et al. [32] argued that the potential cost of damage from earthquakes should be added to lifecycle costs when evaluating long-term building performance. Nevertheless, it remains very difficult to estimate property losses caused by natural hazards, as both their frequency and intensity are inherently random and uncertain [12]. 
Due to global warming, unexpected natural disasters have been increasing in frequency, driving up lifecycle costs during buildings' operation and management stage. In addition, high-performance and high-rise buildings - which are increasingly prevalent due to accelerating urbanization and population growth-have special vulnerabilities to natural hazards, as shown in previous studies on this aspect of lifecycle cost $[12,30]$. The present paper tackles these problems directly, by proposing a lifecycle-cost assessment method that covers not only expected costs such as routine repairs, but also the exceptional ones associated with natural hazards across buildings' entire lifecycles.

\section{Research Methods}

\subsection{Case-Study Approach and Research Process}

In this study, we investigated the relationship between natural disasters and the operation and management costs of a hotel chain that is currently one of the largest of its kind in the world, comprising more than two dozen brands and over 5000 properties around the globe. Despite their geographic dispersal, these properties are similar in terms of construction quality, construction type, and exterior design, among other characteristics. Therefore, their guidelines and methods for estimating lifecycle costs, including operation and management costs, should also be similar. This research relied on the data on 725 incidents of gross losses from natural hazards that this hotel chain incurred from early 2007 to late 2017. The most prevalent type of damage was water-related-a category including floods, overflow, and water-supply facility failures-which comprised $44 \%$ of all damage by the number of reported incidents. The second most prevalent was wind-related, including but not limited to hurricanes and typhoons, which comprised $17 \%$ of all damage. Other natural disaster-related damage, including but not limited to earthquakes, hail, and wildfires together made up an additional $1 \%$. Prominent among the non-disaster-related incidents that accounted for the remaining $38 \%$ of all damage included HVAC failures (13\%), fires $(6 \%)$, and extreme cold $(2 \%)$.

First, the characteristics of the particular natural disasters that affected the hotel chain's properties were categorized as independent variables. Second, the gross loss data were categorized according to the natural hazards that caused them. In this step, claim-payout amounts served as the dependent variable as a proxy for operation and management costs, while the causes of damage were utilized as the independent variables. Third, a regression analysis was conducted to establish the relationships of the independent and dependent variables. Those variables are described below, along with this study's data-collection procedures and statistical analysis methods.

\subsection{Dependent Variable}

Losses from individual events that caused damage during the period of interest ranged from less than $\$ 10,000$ to $\$ 57,445,698$. The smallest single payout was $\$ 37$.

\subsection{Independent Variables}

Although lifecycle-cost assessment can be utilized to design buildings to cope with natural hazards, the expected costs of natural-hazard damage related specifically to building loading are often minimized, which could cause problems [33-35].

According to Harvard's Joint Center for Housing Studies [36], repair costs related to all types of natural disasters made up $8.2 \%$ of all improvement expenditures by homeowners in the United States in 2013. At USA $\$ 15.8$ billion, these hazard repairs were also among the most costly of the 54 categories of expenditure in the same study.

Ayyub [37] emphasized that, among all types of natural disasters, earthquakes were the most severe from the point of view of damage to buildings and infrastructure systems while also having substantial effects on society, the economy, and the environment. Wei et al. [32] noted that many researchers have sought to reduce structures' seismic response, but relatively few have focused on 
the costs of earthquake-related damage over the course of a building's lifecycle. The intensity of earthquakes is usually represented as peak ground acceleration (PGA) [12].

Hurricanes, for their part, can also be very damaging to buildings and infrastructure systems. Their severity can be characterized according to their maximum wind speed radius, forward-motion speed, and sustained maximum wind speed [38-40]. Among these, sustained maximum wind speed and maximum wind speed radius are the main factors utilized to estimate hurricane damage $[38,40,41]$.

However, some research has emphasized the importance of rainfall in the accurate evaluation of the extent of hurricane damage [42,43]. Recently, damage from flooding has also been on the rise, in part due to the effects of urbanization, including the reshaping of river systems [44,45]. Brody et al. [42] highlighted the importance of effective flood control, given that water systems can easily overflow when heavy rain occurs, magnifying flood damage. Therefore, altitude and distance from such systems are useful indicators of water-related hazards that were adopted for this study.

\subsection{Data Collection and Statistical Analysis}

In this study, the wind was measured by wind speed, and earthquakes by PGA, while flooding was measured as a combination of precipitation, the distance from water systems, and the difference in altitude from the nearest water system (Table 1). Data on the first three of these (i.e., wind speed, earthquakes, and flooding) independent variables were provided by the National Oceanic and Atmospheric Administration (NOAA), while the latter two were computed using Google Maps. Data on the dependent variable were provided by the insurers of the hotel chain that participated in this research. To establish correlations between the dependent and independent variables, the ordinary least squares regression method was used.

Table 1. Data types and sources.

\begin{tabular}{|c|c|c|c|}
\hline Variable & Explanation & Measure & Data Source \\
\hline Wind speed & $\begin{array}{c}\text { Sustained maximum } \\
\text { wind speed over } 10 \mathrm{~min}\end{array}$ & $\mathrm{~m} / \mathrm{s}$ & \multirow{3}{*}{$\begin{array}{c}\text { National Oceanic } \\
\text { and Atmospheric } \\
\text { Administration (NOAA) }\end{array}$} \\
\hline $\begin{array}{c}\text { Peak ground } \\
\text { acceleration (PGA) }\end{array}$ & Value of PGA & $\mathrm{g}$ & \\
\hline Precipitation & Total amount of rainfall & $\mathrm{mm} /$ day & \\
\hline Distance from water systems & $\begin{array}{c}\text { Linear distance from } \\
\text { nearest river, lake, } \\
\text { or coastline }\end{array}$ & $\mathrm{m}$ & \multirow{2}{*}{ Google Maps } \\
\hline $\begin{array}{c}\text { Altitude difference } \\
\text { compared to water systems }\end{array}$ & $\begin{array}{l}\text { Altitude difference } \\
\text { compared to the nearest } \\
\text { river, lake, or coastline }\end{array}$ & $\mathrm{m}$ & \\
\hline
\end{tabular}

\section{Results}

\subsection{Descriptive Statistics}

Table 2 presents the descriptive statistics of the variables, with $\mathrm{N}$ standing for the number of data points (i.e., insurance-claim payouts corresponding to at least one of the types of natural disaster considered in this study). 
Table 2. Descriptive statistics of variables.

\begin{tabular}{cccc}
\hline Category & N & Mean & SD \\
\hline $\begin{array}{c}\text { Dependent Variable } \\
\text { and repair costs (Gross loss) (USD) }\end{array}$ & 725 & $271,567.5$ & $2,213,233.9$ \\
Independent Variables & & & \\
Wind speed (m/s) & 725 & 36.6 & 5.1 \\
PGA (g) & 725 & 0.9 & 1.0 \\
Precipitation (mm/day) & 725 & 228.4 & 75.0 \\
Distance from water system (m) & 725 & $55,819.6$ & $741,193.8$ \\
Altitude difference compared to water system (m) & 725 & 368.5 & 3424.3 \\
\hline
\end{tabular}

\subsection{Multiple Regression Analysis}

Normality test of the dependent variable was conducted to verify if the variable followed normal distribution or not before multiple linear regression analysis. The result showed that the significant level of 0.000 was smaller than 0.05 , which means that the dependent variable did not follow a normal distribution. Therefore, the dependent variable was transformed to natural log as follows;

$$
\text { Transformed gross loss }=\text { Log }(\text { Gross loss }(\$))
$$

As seen in Table 3, the result of the normality test with the transformed gross loss showed that the significant value of 0.232 was greater than 0.000 . It was proved that the dependent variable was normally distributed. The histogram and $Q-Q$ plot of Figure 1 confirm that the gross loss followed a normal distribution.
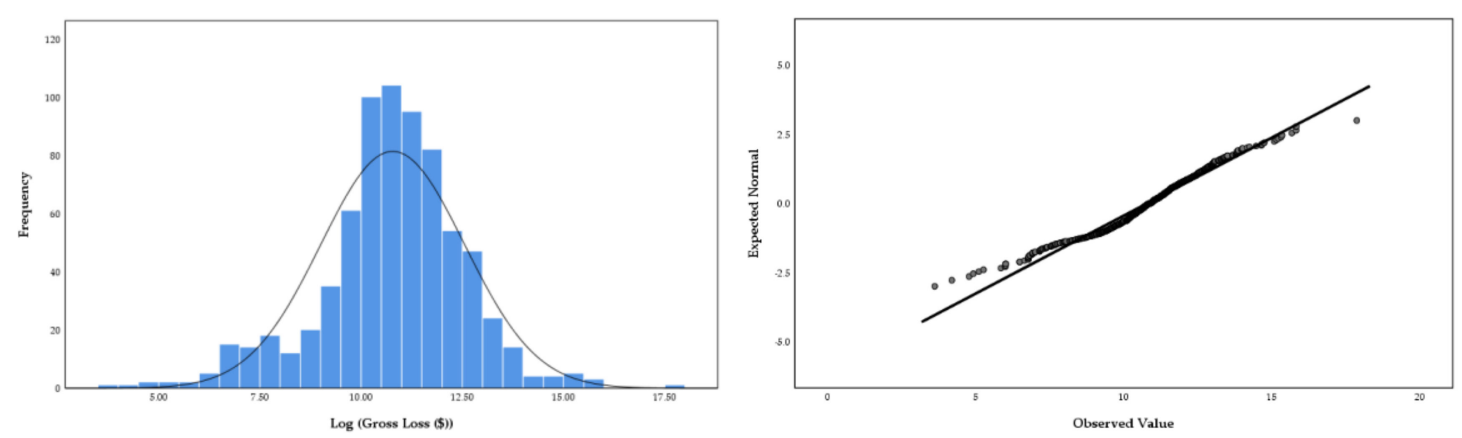

Figure 1. Histogram and $Q-Q$ plot, transformed gross loss.

Table 3. Normality-test results, transformed gross loss.

\begin{tabular}{cccc}
\hline & Statistic & df & Sig. \\
\hline Log Gross loss & 0.972 & 725 & 0.232 \\
\hline
\end{tabular}

The results of our multiple regression analysis for the gross loss connected with natural disasters are shown in Figures 2 and 3 and Table 4. The histogram and $P$-P plot in Figure 2 indicate that the residual of the regression model was normally distributed. The scatter residual plot of the regression model in Figure 3, meanwhile, shows that the variable of the residual was constant, confirming homoscedasticity. In addition, the significance level of 0.000 in Table 4, being smaller than 0.05, indicates that the regression model was statistically significant. It confirms that the relation of the dependent variable to the independent variables was linear. The regression model's $R^{2}$ value was 0.342 , meaning that it can explain $34.2 \%$ of the variation in the dependent variable. The $p$ values indicated that precipitation and the distance from water systems were correlated with the dependent variable, but that the other three independent variables were not. The variance inflation factor (VIF) 
values of this study's variables ranged from 1.002 to 1.114 , which means there was no significant multicollinearity among them.
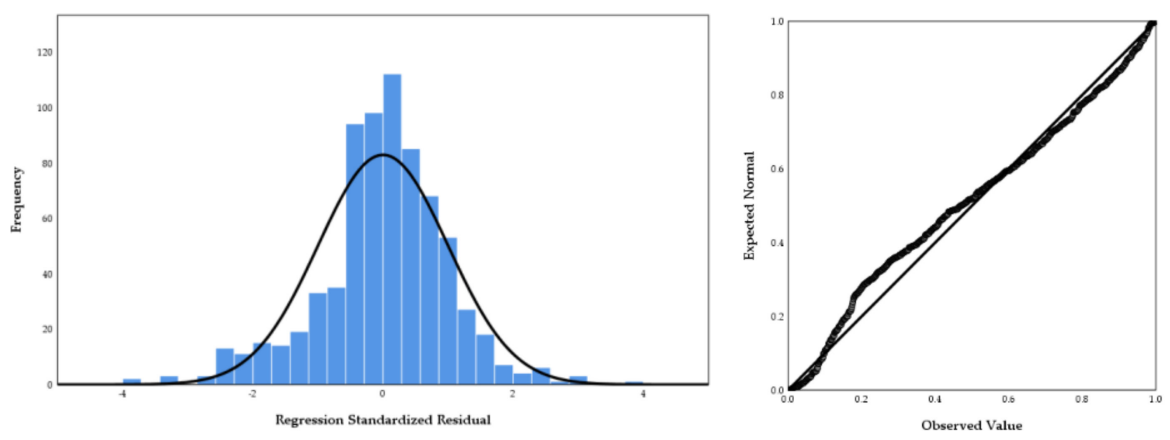

Figure 2. Histogram and $P-P$ residual plot, regression model.

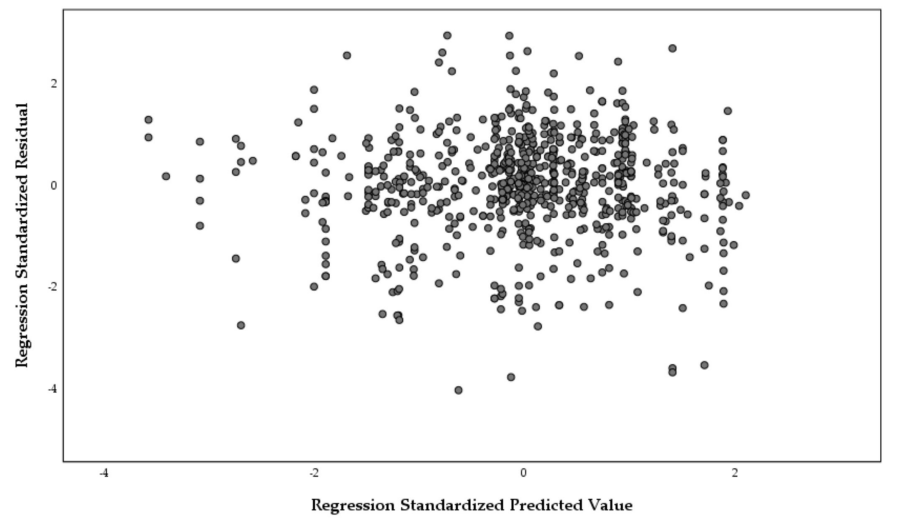

Figure 3. Scatter residual plot, regression model.

Table 4. Regression analysis: final results. VIF: variance inflation factor.

\begin{tabular}{|c|c|c|c|c|c|}
\hline Variables & Coef. & Std. Error & Beta Coef. & $p>|z|$ & VIF \\
\hline Wind speed (m/s) & -0.001 & 0.001 & -0.033 & 0.394 & 1.087 \\
\hline PGA (g) & -0.106 & 0.001 & -0.060 & 0.107 & 1.034 \\
\hline Precipitation (mm/day) & 0.059 & 0.013 & 0.168 & $0.000 *$ & 1.084 \\
\hline Distance from water system $(\mathrm{m})$ & $1.761 \times 10^{-7}$ & 0.000 & 0.074 & $0.045^{*}$ & 1.002 \\
\hline Altitude difference compared to water system (m) & $1.268 \times 10^{-5}$ & 0.000 & 0.024 & 0.527 & 1.114 \\
\hline Number of observations & \multicolumn{5}{|c|}{725} \\
\hline $\mathrm{F}$ & \multicolumn{5}{|c|}{5.350} \\
\hline Sig. & \multicolumn{5}{|c|}{0.000} \\
\hline Adjusted $\mathrm{R}^{2}$ & \multicolumn{5}{|c|}{0.342} \\
\hline
\end{tabular}

A beta coefficient (standard coefficient) was utilized to compare the independent variables, with the highest absolute value being recognized as having the strongest effect on the dependent variable. Table 4 shows that precipitation (0.168) and the distance from water systems (0.074) had higher beta-coefficient values than the other independent variables did.

\section{Discussion}

The research method proposed in this paper offers an opportunity to incorporate loss costs arising from natural hazards into the lifecycle cost, specifically by relating operation and management costs to prior natural disasters. Total worldwide gross property damage caused by high winds, flooding, 
and/or earthquakes during such events cost the insurer of the hotel chain that participated in this study around U.S. $\$ 200$ million in the 2007-2017 period. The correlation between this gross loss and the full set of chosen variables was confirmed as significant.

Among this set, however, the significance of this correlation was accounted for by just two loss factors, precipitation and distance from water systems, both of which had $p$ values $<0.05$ (0.000 for precipitation and 0.045 for distance from water systems). The regression's adjusted $R^{2}$ value $(0.342)$ indicated that $34.2 \%$ of the variation in the dependent variable, gross loss, can be explained by these two loss factors, while the other $65.8 \%$ of the variation in the dependent variable was due to loss factors that were not covered by this research. Thus, through statistical analysis, we discovered that the adopted natural-hazard variables had an important relation to the hotel chain's gross loss.

The findings above reinforce those of previous studies [34,35], which suggest that heavy rainfall and built environments - construction activities or flood-control facilities-are the significant factors in losses arising from natural hazards. Precipitation and distance from water systems are commonly related to flooding damage and, in this case, indicated that heavy rain is likely to cause considerable damage to the hotel chain's properties. An unexpectedly high volume of rain can seep into existing cracks in buildings, leading to severe damage to their interiors, including furniture, partition walls, and other internal structural components. Usually, hotels' basements are used to store essential equipment, but when heavy rain occurs to the point that water systems overflow, basements are very susceptible to inundation.

The identified correlation between two types of natural hazards and gross loss is potentially useful to professionals and policymakers concerned with hotel operations and catastrophe management, as this finding goes some way in addressing the absence of disaster losses in operation and management costs in traditional lifecycle-cost estimation. The present study's findings should also enable insurance companies to modify their business models and/or premium prices based on natural-hazard loss factors and estimates of maximum loss, risk exposure, the probabilities of certain events occurring, and so forth. Likewise, construction companies building hotel facilities may wish to reassess their designs, materials, building features, and safety guidelines from the point of view of vulnerability to precipitation and distance from water systems. In short, the present study confirms that facility management will be greatly enhanced if due consideration is given to natural disasters as important factors in lifecycle costs, especially when-as is the case here-actual gross loss costs can be used in lifecycle-cost estimation.

\section{Conclusions}

The purpose of this study was to explore the relationship between costs arising from natural hazards, both in the broad context of lifecycle-cost estimation and the narrower one of operation and management. It demonstrated the value of incorporating the most damaging types of frequent natural disasters as lifecycle-cost variables through quantitative analysis of the actual gross losses suffered. Even though this research was limited to properties belonging to a single hotel chain, the global nature of that chain increases the likelihood that its findings may be generalizable to other such chains and other types of property portfolios.

Nevertheless, future research should incorporate more resources related to building features such as area, height, material, and price, as well as type-of-damage data (e.g., at a minimum, whether the damage is structural vs. non-structural), as part of the ongoing quest for optimally effective means of managing lifecycle costs. Additionally, to broaden the concept of buildings' long-term sustainability, environmental risks such as proximity to land areas with mountain slopes altered by human activity should be taken into account, since such changes can increase the chance of avalanches $[44,46]$. Additional loss factors such as the radius and forward-movement speeds of hurricanes, areas of basin, and vegetation types should also be considered, especially in light of the present work's relatively low adjusted $R^{2}$. 
A balanced consideration of social, economic, and environmental impacts is necessary if a complete picture of buildings' long-term sustainability, and thus their lifecycle cost, is to be achieved. Accordingly, future research should give due consideration to energy consumption, $\mathrm{CO}_{2}$ emissions, and other environmentally relevant factors during construction and end-of-life demolition, as well as costs such as water, lighting, garbage disposal, and mechanical, electrical, and plumbing (MEP) systems during the operation and management phase. It should also be noted that the present research did not account for variations in the climate or local economies of the locations of the hotel's different properties, which may mean that its approach cannot be generalized to all locations. Thus, future research should give greater consideration to geographic variation in climate, local economies, and construction/repair costs to ensure that the proposed approach to lifecycle-cost estimation can be applied accurately in a full range of global contexts. In such future projects, artificial neural networks (ANNs) would be a useful tool for investigating complex non-linear relationships among research variables, for identifying independent variables, and for optimizing the process through training and testing phases in such future research; this would be valuable not only for initial-stage cost estimation but also during other phases of construction and other aspects of construction-project management.

Researchers could also use BIM in such research by including natural disasters as n-D, followed by $4 \mathrm{D}$ modeling that includes construction scheduling in the 3D model. The insurance industry is already using catastrophe-modeling techniques to predict damage from natural hazards, estimate maximum losses, and adjust premium prices. Similarly, facility-management companies looking to manage their properties more effectively by reducing unexpected costs could use the results of the present research as a basis for hazard mapping or hazard-prediction modeling at regional and national levels, combining $\mathrm{n}$-D modeling or catastrophe modeling as mentioned above, because such models can estimate the value of unexpected potential loss from natural disasters. Moreover, fragility or vulnerability curves including building information such as building history, number of floors, locations, and building codes corresponding to wind speed and/or distance from water systems could be usefully included in future research on risk assessment for hotel properties.

Author Contributions: Conceptualization, S.-G.Y.; Data curation, S.-G.Y. and J.-M.K.; Funding acquisition, J.-M.K.; Investigation, S.-G.Y.; Methodology, S.-G.Y.; Project administration, K.S.; Software, J.-M.K.; Supervision, K.S.; Validation, S.-G.Y. and J.-M.K.; Resources, J.-M.K.; Writing—original draft, J.-M.K.; Writing-review \& editing, S.-G.Y. and K.S. All authors have read and agreed to the published version of the manuscript.

Funding: This research was funded by the Basic Science Research Program through the National Research Foundation of Korea (NRF) funded by the Ministry of Education (NRF-2019R1F1A1058800).

Conflicts of Interest: The authors declare no conflict of interest.

\section{References}

1. Kim, S.; Jin, R.; Hyun, C.; Cho, C. Development of operation \& maintenance cost estimating model for facility management of buildings. J. Archit. Inst. Korea 2013, 29, 11-21.

2. Sung, M.; Kim, K.; Yu, J. Development of BIM-based information management model for efficient building maintenance. Proc. Korean Inst. Build. Constr. 2011, 11, 137-140.

3. FEMA (Federal Emergency Management Agency). HAZUS-MH Estimated Annualized Earthquake Losses for the United States; FEMA: Washington, DC, USA, 2008.

4. Rein, A.; Corotis, R.B. An overview approach to seismic awareness for a 'quiescent' region. Nat. Hazard. J. 2013, 67, 335-363. [CrossRef]

5. Remo, J.W.; Pinter, N. HAZUS-MH earthquake modeling in the central USA. Nat. Hazard. J. 2012, 63, 1055-1081. [CrossRef]

6. Tantala, M.W.; Nordenson, G.J.; Deodatis, G.; Jacob, K. Earthquake loss estimation for the New York City metropolitan region. Soil Dyn. Earthq. Eng. J. 2008, 28, 812-835. [CrossRef]

7. Intergovernmental Panel on Climate Change (IPCC). Contribution of Working Group I to the Fourth Assessment Report of the Intergovernmental Panel on Climate Change; Cambridge University Press: Cambridge, UK, 2007.

8. Sissine, F. Energy Independence and Security Act of 2007: A Summary of Major Provisions; Library of Congress Washington DC Congressional Research Service: Washington, DC, USA, 2007. 
9. Brown, N.A.; Orchiston, C.; Rovins, J.E.; Feldmann-Jensen, S.; Johnston, D. An integrative framework for investigating disaster resilience within the hotel sector. J. Hosp. Tour. Manag. 2018, 36, 67-75. [CrossRef]

10. Brown, N.A.; Rovinsa, J.E.; Feldmann-Jensenb, S.; Orchistonc, C.; Johnston, D. Exploring disaster resilience within the hotel sector: A systematic review of literature. Int. J. Disaster Risk Reduct. 2017, 22, 362-370. [CrossRef]

11. Brown, N.A.; Rovinsa, J.E.; Feldmann-Jensenb, S.; Orchistonc, C.; Johnston, D. Measuring disaster resilience within the hotel sector: An exploratory survey of Wellington and Hawke's Bay, New Zealand hotel staff and managers. Int. J. Disaster Risk Reduct. 2019, 33, 108-121. [CrossRef]

12. Noshadravan, A.; Miller, T.R.; Gregory, J.G. A lifecycle cost analysis of residential buildings including natural hazard risk. J. Constr. Eng. Manag. 2017, 143, 04017017-1-10. [CrossRef]

13. Teicholz, E. Bridging the AEC/FM technology gap. J. IFMA Facil. Manag. 2004, 2, 1-8.

14. Chae, M.; Lee, G.; Kim, J.; Cho, M. Analysis of domestic and international infrastructure asset management practices and improvement strategy. Korean J. Constr. Eng. Manag. 2009, 10, 55-64.

15. Lee, K.-J.; Jung, Y.-S. Assessment of facility management functions for life-cycle information sharing. Korean J. Constr. Eng. Manag. 2016, 17, 40-52. [CrossRef]

16. Yu, K.; Froese, T.; Grobler, F. A development framework for data models for computer-integrated facilities management. J. Autom. Constr. 2000, 9, 145-167. [CrossRef]

17. Foster, B. BIM for facility management: Design for maintenance strategy. J. Build. Inf. Model. 2011, 2011, 18-19.

18. Williams, R.; Shayesteh, H.; Marjanovic-Halburd, L. Utilizing building information modeling for facilities management. Int. J. Facil. Manag. 2014, 5, 1-19.

19. American Society for Testing and Materials (ASTM). Standard Practice for Measuring Payback for Investments in Buildings and Building Systems; ASTM E1121-12; ASTM: West Conshohocken, PA, USA, 2012.

20. American Society for Testing and Materials (ASTM). Standard Practice for Measuring Life-Cycle Costs of Buildings and Building Systems; ASTM E917-13; ASTM: West Conshohocken, PA, USA, 2013.

21. Pettang, C.; Mbumbia, L.; Foudjet, A. Estimating building materials cost in urban housing construction projects, based on matrix calculation: The case of Cameroon. J. Constr. Build. Mater. 1997, 11, 47-55. [CrossRef]

22. Günaydın, H.M.; Doğan, S.Z. A neural network approach for early cost estimation of structural systems of buildings. Int. J. Proj. Manag. 2004, 22, 595-602. [CrossRef]

23. Kim, G.-H.; An, S.-H.; Kang, K.-I. Comparison of construction cost estimating models based on regression analysis, neural networks, and case-based reasoning. J. Build. Environ. 2004, 39, 1235-1242. [CrossRef]

24. Rahman, S.; Perera, S.; Odeyinka, H.; Bi, Y. A Conceptual Knowledge-Based Cost Model for Optimizing the Selection of Materials and Technology for Building Design. In Proceedings of the 24th Annual Association of Research in Construction Management, Cardiff, UK, 1-3 September 2008.

25. Hasan, A. Optimizing insulation thickness for buildings using life cycle cost. J. Appl. Energy 1999, 63, 115-124. [CrossRef]

26. Kneifel, J. Life-cycle carbon and cost analysis of energy efficiency measures in new commercial buildings. J. Energy Build. 2010, 42, 333-340. [CrossRef]

27. Morrissey, J.; Horne, R. Life cycle cost implications of energy efficiency measures in new residential buildings. J. Energy Build. 2011, 43, 915-924. [CrossRef]

28. Gluch, P.; Baumann, H. The life cycle costing (LCC) approach: A conceptual discussion of its usefulness for environmental decision-making. J. Build. Environ. 2004, 39, 571-580. [CrossRef]

29. De Silva, D.G.; Kruse, J.B.; Wang, Y. Spatial dependencies in wind-related housing damage. Nat. Hazard. J. 2008, 47, 317-330. [CrossRef]

30. Khanduri, A.; Morrow, G. Vulnerability of buildings to windstorms and insurance loss estimation. J. Wind Eng. Ind. Aerodyn. 2003, 91, 455-467. [CrossRef]

31. Chang, S.E.; Shinozuka, M. Life-cycle cost analysis with natural hazard risk. J. Infrastruct. Syst. 1996, 2, 118-126. [CrossRef]

32. Wei, H.-H.; Shohet, I.M.; Skibniewski, M.J.; Shapira, S.; Yao, X. Assessing the lifecycle sustainability costs and benefits of seismic mitigation designs for buildings. J. Archit. Eng. 2016, 22, 04015011. [CrossRef]

33. Liu, M.; Burns, S.A.; Wen, Y. Optimal seismic design of steel frame buildings based on life cycle cost considerations. J. Earthq. Eng. Struct. Dyn. 2003, 32, 1313-1332. [CrossRef] 
34. Wen, Y.K.; Kang, Y.J. Minimum building life-cycle cost design criteria. II: Applications. J. Struct. Eng. 2001, 127, 338-346. [CrossRef]

35. Wen, Y.K.; Kang, Y.J. Minimum building life-cycle cost design criteria. I: Methodology. J. Struct. Eng 2001, 127, 330-337. [CrossRef]

36. JCHS (Joint Center for Housing Studies of Harvard University). Improving America's Housing 2015: Emerging Trends in the Remodeling Market; Harvard University: Cambridge, MA, USA, 2015.

37. Ayyub, B.M. Risk Analysis in Engineering and Economics; Chapman \& Hall/CRC: Boca Raton, FL, USA, 2003.

38. Burton, C.G. Social vulnerability and hurricane impact modeling. J. Nat. Hazards Rev. 2010, 11, 58-68. [CrossRef]

39. Dunion, J.P.; Landsea, C.W.; Houston, S.H.; Powell, M.D. A reanalysis of the surface winds for Hurricane Donna of 1960. J. Mon. Weather Rev. 2003, 131, 1992-2011. [CrossRef]

40. Vickery, P.J.; Skerlj, P.F.; Lin, J.; Twisdale, L.A., Jr.; Young, M.A.; Lavelle, F.M. HAZUSMH hurricane model methodology. II: Damage and loss estimation. J. Nat. Hazards Rev. 2006, 7, 94-103. [CrossRef]

41. Watson, C., Jr.; Johnson, M.E. Hurricane loss estimation models: Opportunities for improving the state of the art. J. Bull. Am. Meteorol. Soc. 2004, 85, 1713-1726. [CrossRef]

42. Brody, S.D.; Zahran, S.; Highfield, W.E.; Grover, H.; Vedlitz, A. Identifying the impact of the built environment on flood damage in Texas. J. Disasters 2008, 32, 1-18. [CrossRef]

43. Choi, O.; Fisher, A. The impacts of socioeconomic development and climate change on severe weather catastrophe losses: Mid-Atlantic Region (MAR) and the US. J. Clim. Chang. 2003, 58, 149-170. [CrossRef]

44. Cui, B.; Wang, C.; Tao, W.; You, Z. River channel network design for drought and flood control: A case study of Xiaoqinghe River basin, Jinan City, China. J. Environ. Manag. 2009, 90, 3675-3686. [CrossRef]

45. Zhai, G.; Fukuzono, T.; Ikeda, S. Multi-attribute evaluation of flood management in Japan: A choice experiment approach. Water Environ. J. 2007, 21, 265-274. [CrossRef]

46. Dai, F.; Lee, C.; Ngai, Y.Y. Landslide risk assessment and management: An overview. J. Eng. Geol. 2002, 64, 65-87. [CrossRef]

(C) 2020 by the authors. Licensee MDPI, Basel, Switzerland. This article is an open access article distributed under the terms and conditions of the Creative Commons Attribution (CC BY) license (http://creativecommons.org/licenses/by/4.0/). 